\title{
ON AN EXTENSION OF SAKAGUCHI'S RESULT
}

\author{
MAMORU NunOKAWA AND JANUSZ SOKÓŁ
}

Abstract. We improve Pommerenke's result [15] by using a generalized lemma from [11]. It gives an extension of Sakaguchi's result too, [18]. Several applications of main theorems are presented. A part of them improves the previous results of this type. We consider also Sakaguchi's result under different type of the assumptions.

Mathematics subject classification (2010): Primary 30C45; Secondary 30C80.

Keywords and phrases: Analytic functions, convex functions, univalent functions, Jack's Lemma, Nunokawa's Lemma.

\section{REFERENCES}

[1] S. Fukui, K. Sakaguchi, An extension of a theorem of S. Ruscheweyh, Bull. Fac. Edu. Wakayama Univ. Nat. Sci. 29 (1980) 1-3.

[2] A. W. Goodman, Univalent Functions, Vol. II, Mariner Publishing Co.: Tampa, Florida (1983).

[3] I. S. JACK, Functions starlike and convex of order $\alpha$, J. London Math. Soc. 3 (1971) 469-474.

[4] W. Kaplan, Close to convex schlicht functions, Michigan Math. J. 1 (1952) 169-185.

[5] Z. LEWANDOWs KI, Sur l'identité de certaines classes de fonctions univalentes, I. Ann. Univ. Mariae Curie-Skłodowska Sect. A 12 (1958) 131-146.

[6] Z. LEWANDOWs Ki, Sur l'identité de certaines classes de fonctions univalentes, II. Ann. Univ. Mariae Curie-Skłodowska Sect. A 14 (1960) 19-46.

[7] R. J. Libera, Some classes of regular univalent functions, Proc. Amer. Math. Soc., 16 (1965) 755758.

[8] T. H. MacGregor, A subordination for convex function of order $\alpha$, J. London Math. Soc. 2 (9) (1975) 530-536.

[9] S. S. Miller, P. T. Mocanu, Differential subordinations: theory and applications, Series of Monographs and Textbooks in Pure and Applied Mathematics, Vol. 225, Marcel Dekker Inc., New York/Basel 2000.

[10] P. T. Mocanu, D. Ripeanu, M. Popovici, Best bound for the argument of certain analytic functions with positive real part, Babeş-Bolyai Univ., Fac. of Math. Res. Sem., Seminar of geometric Function Theory, Preprint 5 (1986) 91-98.

[11] M. Nunokawa, On Properties of Non-Carathéodory Functions, Proc. Japan Acad. Ser. A 68 (6) (1992) 152-153.

[12] M. NUNOKAWA, On the order of strongly starlikeness of strongly convex functions, Proc. Japan Acad. Ser. A 69 (7) (1993) 234-237.

[13] M. Nunokawa, S. Owa, E. Yavuz Duman And M. Aydogan, Some properties of analytic functions relating to the Miller and Mocanu results, Comp. Math. Appl., 61 (2011) 1291-1295.

[14] S. OZAKI, On the theory of multivalent functions, Sci. Rep. Tokyo Bunrika Daig. A 2 (1935) 167-188.

[15] Ch. Pommerenke, On close-to-convex analytic functions, Trans. Amer. Math. Soc., 114 (1969) $176-186$.

[16] S. Ponnusmy, V. Karunakakaran, Differential subordination and conformal mappings, Complex variable, 11 (1989) 79-86.

[17] M. READE, The coefficients of close-to-convex functions, Duke Math. J. 23 (1956) 459-462.

[18] K. SaKaguchi, On certain univalent mapping, J. Math. Soc. Japan, 11 (1959) 72-75.

[19] J. SoKóŁ, On sufficient condition to be in a certain subclass of starlike functions defined by subordination, Appl. Math. Comput. 190 (2007), no. 1, 237-241. 
[20] J. SoKó£, Starlikeness of the Libera transform of functions with bounded turning, Appl. Math. Comput. 203 (2008), no. 1, 273-276.

[21] J. SoKóŁ, On Neighborhoods of analytic functions having positive real part, Mathematische Nachrichten 284 (11-12) (2011) 1547-1553.

[22] E. Study, Konforme Abbildung Einfachzusammenhangender Bereiche, B. C. Teubner, Leipzig und Berlin 1913.

[23] T. UmeZawa, On the theory of univalent functions, Tohoku Math. J. 7 (1955) 212-228.

[24] T. UmeZawa, Multivalently close-to-convex functions, Proc. Amer. Math. Soc. 8 (1957) 869-874. 